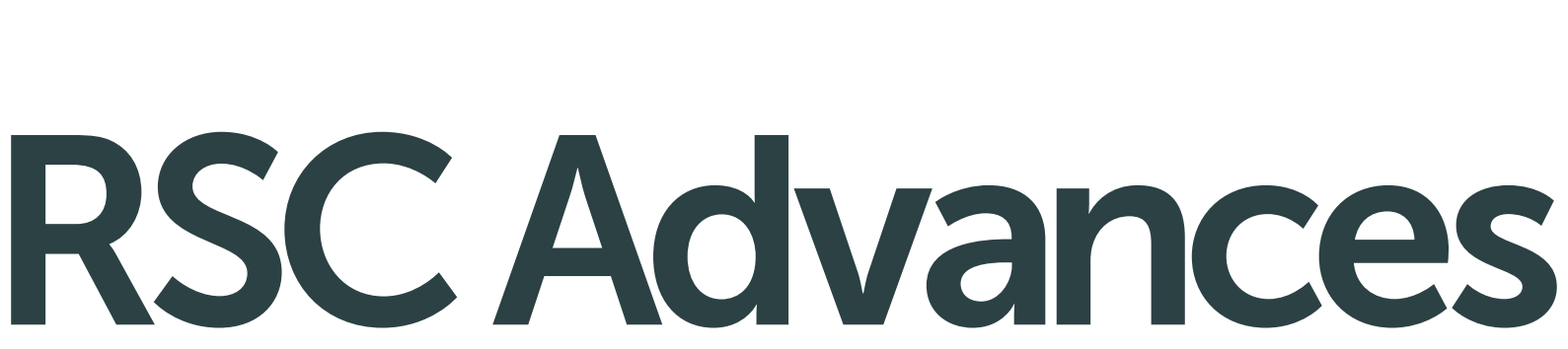

This article can be cited before page numbers have been issued, to do this please use: S. Panneri, N. Kumar, N. Madhavan, D. Kumar, B. N. Nair, A. M. Peer, K. G. K. Warrier and H. U. N. Saraswathy, RSC Adv., 2015, DOI: 10.1039/C5RA13316E.
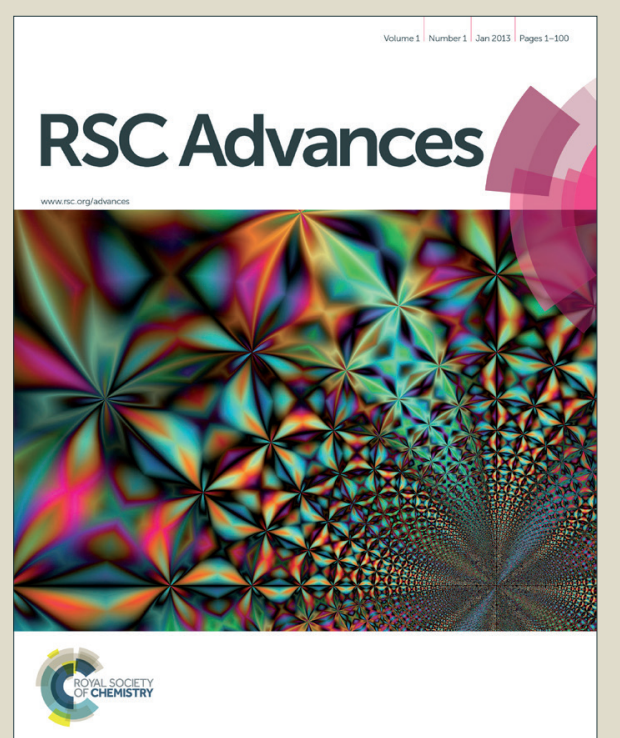

This is an Accepted Manuscript, which has been through the Royal Society of Chemistry peer review process and has been accepted for publication.

Accepted Manuscripts are published online shortly after acceptance, before technical editing, formatting and proof reading. Using this free service, authors can make their results available to the community, in citable form, before we publish the edited article. This Accepted Manuscript will be replaced by the edited, formatted and paginated article as soon as this is available.

You can find more information about Accepted Manuscripts in the Information for Authors.

Please note that technical editing may introduce minor changes to the text and/or graphics, which may alter content. The journal's standard Terms \& Conditions and the Ethical guidelines still apply. In no event shall the Royal Society of Chemistry be held responsible for any errors or omissions in this Accepted Manuscript or any consequences arising from the use of any information it contains. 


\title{
Reactive Oxygen Species (ROS) Mediated Enhanced Anti-candidal Activity of ZnS-ZnO Nanocomposites with Low Inhibitory Concentrations
}

\section{P. Suyana ${ }^{a}$, S. NishanthKumar ${ }^{b}$, NimishaMadhavan ${ }^{a}$, B. S. DileepKumar ${ }^{\text {b,d }}$, Balagopal N.

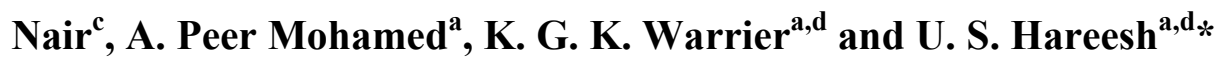

${ }^{\mathrm{a}}$ Material Science and Technology Division

${ }^{\mathrm{b}}$ Agroprocessing and Natural Products Division

National Institute for Interdisciplinary Science and Technology (CSIR-NIIST)

Thiruvananthapuram-695019, India

${ }^{c}$ R\& D Centre, Noritake Co. Limited, Aichi 470-0293, Japan

${ }^{\mathrm{d}}$ Academy of Scientific and Innovative Research, New Delhi, India

*Corresponding author E-mail: hareesh@,niist.res.in

Telephone: 00914712535504

Fax: 00914712491712

\begin{abstract}
Enhanced antifungal activity against the yeast species of Candida albicans, Candida tropicalis and Saccharomyces cerevisiae was displayed by $\mathrm{ZnS}-\mathrm{ZnO}$ nanocomposites prepared by a simple precipitation technique. The antifungal activity was significantly more in the presence of indoor light than under dark conditions and was a clear confirmation of the inhibitory role of reactive oxygen species (ROS) generated insitu by the photocatalytic nanocomposites. The generation of ROS was further evidenced by flow cytometry results and membrane permeabilisation studies. Time kill assay and growth curve analysis indicated diminished antifungal activity under dark conditions due primarily to $\mathrm{Zn}^{2+}$ efflux in solution.
\end{abstract}




\section{Introduction}

Semiconductor nanoparticles are employed in recent years as an environmentally benign solution for pollution control as well as for the disinfection of harmful microbes like Escherichia coli, Staphylococcus aureus, and Candida albicans. ${ }^{1-7}$ Advanced oxidation process based on semiconductor mediated photocatalytic degradation of the pollutants and microbes is the primary mechanism underlying this technique. ${ }^{8-9}$ Unlike other methods, photocatalytic disinfection or degradation is simple, cost effective, and safe as only light is needed as energy source and no harmful by-products are released. ${ }^{10-11}$ Semiconductors like $\mathrm{TiO}_{2}, \mathrm{ZnO}, \mathrm{ZnS}$, etc are proven to be effective materials for the photocatalytic degradation of the organic compounds and disinfection of microbes. ${ }^{12-19}$

$\mathrm{ZnS}$ is an important semiconductor whose theoretical photocarrier efficiency is much higher than $\mathrm{TiO}_{2} \cdot{ }^{20}$ It is one of the first semiconductors invented and has wide range of applications in electronic, optical, biomedical, and photovoltaic devices. The unique size dependent properties $\mathrm{ZnS}$ nanoparticles enable its wide spread applications in solar cells, LEDs, catalysis, and as sensors and antimicrobial agents. Due to its high energy conversion efficiency and the relatively negative redox potential of conduction band, it has been well suited for application as a photocatalyst. $^{21-22}$ However, owing to its large bandgap, $\mathrm{ZnS}$ is active only in the UV region and more efficient visible light harvesting would render this material quite attractive for practical applications in the area of photocatalysis and photovoltaics.

A simple and cost effective strategy to improve the activity of $\mathrm{ZnS}$ is to develop nanocomposites with compatible semiconductors. The synergistic effects of individual semiconductors could lead to more effective electron-hole pair separation by retarding the recombination process. ${ }^{23-}$ 
${ }^{24} \mathrm{Among}$ these, $\mathrm{ZnS}-\mathrm{ZnO}$ nanocomposites is a priority choice by virtue of its lower photoexcitation threshold energy and improved electron transfer paths than the individual components.$^{25}$ The large difference in electronegativity values and sizes between $\mathrm{S}$ and $\mathrm{O}$ modify the electrical and optical properties of $\mathrm{ZnS}-\mathrm{ZnO}$ combinations. ${ }^{26-27}$ The nanocomposites thus promote the electron transfer process with photogenerated electrons flowing from $\mathrm{ZnS}$ to $\mathrm{ZnO}^{22}$ The recombination rate of the charge carriers thus decrease immensely as a result of their physically separated band gap. Till date, many experimental methodologies are reported for the effective synthesis of $\mathrm{ZnS}-\mathrm{ZnO}$ composites. ${ }^{28-32}$ Most of the available reports are focused on development of heterostructured $1 \mathrm{D} \mathrm{ZnO} / \mathrm{ZnS}$ nanowires, nanoribbons, nanocables or nanobelts for various applications like electricity generation, luminescent applications, sensors, optoelectronic devices etc. However the preparation methods require sophisticated conditions to obtain the heterostructures. $^{30,32-35}$

In the present work a simple water based co-precipitation technique was employed for the synthesis of $\mathrm{ZnS}-\mathrm{ZnO}$ nanocomposites. The prepared nanocomposites were tested for their antimicrobial activity against the important yeast species of Candida albicans (C. albicans),Candida tropicalis(C. tropicalis) and Saccharomyces cerevisiae (S. cerevisiae) and their minimum inhibitory concentrations were elucidated. To the best of our knowledge this is the firststudy employing $\mathrm{ZnS}-\mathrm{ZnO}$ nanocomposites for antimicrobial applications. The generation and role of reactive oxygen species (ROS) in reducing the microbial burden was identified by flow cytometry measurements. Damage of cell membrane due to ROS was studied by cell permeabilisation studies using propidium iodide uptake assay. A systematic evaluation employing time kill assay and growth curves under light and dark conditions permitted comprehensive analysis of the inhibitory role of photo induced ROS in fungal growth. 


\section{Experimental}

\subsection{Synthesis of $\mathrm{ZnS}-\mathrm{ZnO}$ nanocomposites}

In a typical synthesis, aqueous solution of sodium hydroxide $(1.0 \mathrm{M})$ was added drop by drop to an aqueous solution of zinc nitrate hexahydrate $(0.5 \mathrm{M})$ and the mixture was stirred for 3 hours.

The $\mathrm{ZnO}$ thus obtained was added drop wise to an aqueous solution of zinc acetate dihydrate $(0.5$ M) with constant stirring. An aqueous solution of sodium sulphide $(0.5 \mathrm{M})$ was then added and stirring was continued for 1 hour. The thick white precipitate obtained was filtered, washed with distilled water, and dried at $100^{\circ} \mathrm{C}$. Three different compositions of $\mathrm{ZnS}$ : $\mathrm{ZnO}$ containing 3:1, 1:1, and 1:3 weight ratios were prepared and are denoted as ZSO31, ZSO11, and ZSO13 respectively here after. Pure $\mathrm{ZnS}$ was prepared using zinc acetate and sodium sulphide through a simple precipitation method.

\subsection{Characterization of photocatalyst}

The prepared nanocomposites were characterized by X-ray diffraction (Philips X'pert Pro diffractometer) in the $2 \theta$ range of $10-80^{\circ}$ using $\mathrm{Cu} \mathrm{K} \alpha$ radiation to evaluate the crystal structure and purity. BET surface area measurements were carried out using a BET surface area analyser (Gemini 2375, Micromeritics, USA) after degassing the samples at $200^{\circ} \mathrm{C}$ for 2 hours.SEM images were acquired on an EVO 18Special Edition scanning electron microscope (Carl Zeiss, Germany) operating at $20 \mathrm{kV}$. The morphology of the nanocrystallites was observed through a high resolution transmission electron microscope (HRTEM, FEI Tecnai $30 \mathrm{G}^{2} \mathrm{~S}-\mathrm{TWIN}$ ) operated at an accelerating voltage of $300 \mathrm{kV}$. The diffused reflectance spectra of the prepared materials were analyzed using a spectrophotometer in the spectral band width of 200-800 nm (Shimadzu UV 2401 PC). 


\subsection{Antimicrobial study}

\subsubsection{Growth condition and maintenance of test organisms}

The test yeast strains used in the study were Candida albicans MTCC 277,Candida tropicalis MTCC 184, and Saccharomyces cerevisiae MTCC 463 procured from the Microbial Type Culture Collection and Gene Bank (MTCC) Division, CSIR-Institute of Microbial Technology (IMTECH), Chandigarh, India. Stock culture was maintained on slants of PD agar (containing dextrose $40 \mathrm{~g}^{-1}$, peptone $10 \mathrm{~g}^{-1}$ and agar $15 \mathrm{~g} \mathrm{l}^{-1}$ ) at $4^{\circ} \mathrm{C}$. The primary culture of theyeast species was prepared from the stock slant into the PD broth medium and incubated at $30^{\circ} \mathrm{C}$ for $48 \mathrm{~h}$ (stationary phase, $\left.10^{8} \mathrm{CFU} / \mathrm{ml}\right)$. The primary culture $(1 \mathrm{ml})$ was re-inoculated into the $50 \mathrm{ml}$ fresh PD broth and grown for $12 \mathrm{~h}$ up to mid-log phase (approx. $10^{5} \mathrm{CFU} / \mathrm{ml}$ ) at $30^{\circ} \mathrm{C}$. All experiments were performed from the mid-log phase $\left(10^{5} \mathrm{CFU} / \mathrm{ml}\right)$ freshly grown yeastspp. culture in triplicates.

\subsubsection{Minimum inhibition concentration (MIC)}

The MIC is the lowest concentration at which a material exhibits antimicrobial activity and this was done by serial dilution technique according Clinical and Laboratory standard Institute (CLSI). Sterile test tubes were taken separately with $9.9 \mathrm{ml}$ of saline water, inoculated with $10^{5}$ $\mathrm{CFU} / \mathrm{ml}$ of corresponding microorganisms. To this, different concentrations $(2-500 \mathrm{mg} / \mathrm{ml})$ of ZSO31, ZSO11, and ZSO13 were added to individual test tubes. The whole setup was allowed to grow overnight at for $48 \mathrm{~h}$. Negative and positive control tubes contained only inoculated broth and free nanoparticles suspension. Compounds were tested three times and the results were averaged. The visual turbidity of the tubes was noted before and after incubation. The MIC was estimated as lowest concentration of the nanoparticles that did not permit any visible growth of microbes during $24 \mathrm{~h}$ of incubation on the basis of turbidity. To avoid the possibility of 
misinterpretations due to the turbidity of insoluble compounds, if any, the MIC was determined by subculturing the above serial dilutions after $24 \mathrm{~h}$ and plated in PD agar.

\subsubsection{Effect of nanoparticles on yeast spp. by studying the Growth kinetics}

Yeast spp. was cultured on PD agar plates for $18 \mathrm{~h}$ at $30^{\circ} \mathrm{C}$ before use. MIC concentrations of $\mathrm{ZnO}, \mathrm{ZnS}, \mathrm{ZSO} 31, \mathrm{ZSO} 11$ and ZSO13 nanoparticles were prepared in sterilized PD medium to a final volume of $10 \mathrm{ml}$. A single colony of each yeast spp. was used for inoculating the PDB medium containing the nanoparticles as well as a positive control containing only yeast spp. (without any nanoparticles). Aliquots were taken from $0,1,2,4,6,12,24$, and $48 \mathrm{~h}$ for measurement of the optical density at $600 \mathrm{~nm}$. The plates were incubated at $30^{\circ} \mathrm{C}$ for $48 \mathrm{~h}$. The light source used was a normal household fluorescent lamp. All the experiments under dark were conducted using the suspensions prepared in the dark and culture grown in dark conditions by the culture tubes with aluminum foil.

\subsubsection{Time-kill curve analysis}

A time-kill curve (CFU as a function of time) was evaluated to study the rate and extent of reduction in Candidal burden when treated with MIC concentration of nanoparticles ( $\mathrm{ZnO}$, ZnS, ZSO31, ZSO11, and ZSO13). The experiments were conducted in PDB for $48 \mathrm{~h}$. The concentrations used were the MIC values of corresponding nanoparticles. An initial inoculum of approximately $1 \times 10^{6} \mathrm{CFU} / \mathrm{ml}$ was taken for all the experiments. Samples $(0.1 \mathrm{ml})$ were collected at $0,2,4,6,8,12,24$, and $48 \mathrm{~h}$ and serially diluted in normal saline and aliquoted in onto PDA. These plates were then incubated at $30^{\circ} \mathrm{C}$ for $48 \mathrm{~h}$ and the colonies were counted. The broth without any agent was used as the control. The data were plotted as $\log \mathrm{CFU} / \mathrm{ml}$ versus time (h) for each time point. Tests were performed three times. Significant activity was defined 
as a decrease of $\geq 2 \log _{10} \mathrm{CFU} / \mathrm{ml}$ after $48 \mathrm{~h}$. Lowest limit of quantification of time kill assay was $1 \log _{10} \mathrm{CFU} / \mathrm{ml}(99.99 \%$ reduction).

\subsubsection{Estimation of Intracellular Reactive Oxygen Species (ROS) by flow cytometry analysis}

For the detection of reactive oxygen species (ROS) produced over a $4 \mathrm{~h}$ culture period after the treatment of MIC concentration of nanoparticles, cells were incubated with $20 \mu \mathrm{MCM}-$ $\mathrm{H}_{2}$ DCFDA [5-(and-6)-chloromethyl-2=,7=-dichlorodihydrofluoresceindiacetate acetyl ester] for $30 \mathrm{~min}$ in the dark at $35^{\circ} \mathrm{C}$. The DCFH-DA passively enters the cell where it reacts with ROS to form highly fluorescent dichlorofluorescein (DCF). Then, the cells were harvested, washed, resuspended in PBS, and immediately analyzed by flow cytometry (BD science). $\mathrm{CM}-\mathrm{H}_{2} \mathrm{DCFDA}$ readily diffuses through the cell membrane and is hydrolyzed by intracellular esterases to nonfluorescent dichlorofluorescein (DCFH), which is then rapidly oxidized to highly fluorescent DCF (2', 7'-dichlorofluorescein) as a result of a broad range of intracellular oxidative stresses other than $\mathrm{H}_{2} \mathrm{O}_{2}$. The fluorescence intensity of DCF is proportional to the intracellular amount of ROS formed ${ }^{36}$.

\subsubsection{Membrane Permeabilisation studies due to ROS production}

Permeabilisation of fungal membrane after the combination treatment was checked by using propidium iodide (PI), a membrane impermeable dye. ${ }^{37}$ For this, actively growing C. albicans cells $\left(\sim 1 \times 10^{6} \mathrm{CFU} / \mathrm{ml}\right)$ were suspended in an RPMI-1640 medium containing nanocomposites and PI $(1.49 \mu \mathrm{M})$. After incubation for $1 \mathrm{~h}$ at $30^{\circ} \mathrm{C}$ with constant shaking $(200 \mathrm{rpm})$, cells were harvested by centrifugation and suspended in phosphate buffer saline (PBS, pH 7.4). The cells were then visualized by confocal laser scanning microscopy (BD Pathway ${ }^{\mathrm{TM}}$ Bioimager System, 
BD Biosciences) with a wavelength of $560 \mathrm{~nm}$ for PI. Cells without violacein and azoles served as controls. $^{38}$

\section{Results}

X-ray diffraction, presented in Fig. 1, was used to analyze the crystal structure and phase purity of the prepared samples. The prepared $\mathrm{ZnS}$ crystallized in the cubic sphalerite form while the $\mathrm{ZnO}$ was obtained in hexagonal wurtzite structure. The $\mathrm{ZnS}$ particles were nanosized as indicated by broadened XRD peaks. The $\mathrm{ZnO}$ peaks were highly crystalline and narrow. The composites indicated peaks corresponding to both $\mathrm{ZnS}$ and $\mathrm{ZnO}$. $\mathrm{ZnO}$ has three prominent peaks at $2 \theta=31.7^{0}, 34.4^{0}$, and $36.3^{0}$ corresponding to (100), (002), and (101) planes respectively. $\mathrm{ZnS}$ has three peaks at $28.8^{0}, 48^{0}$, and $56^{0}$ corresponding to (111), (220), and (311) planes. As the concentration of $\mathrm{ZnO}$ increased, the $\mathrm{ZnS}$ peak intensity was found reduced. No other impurities were present in the composites.

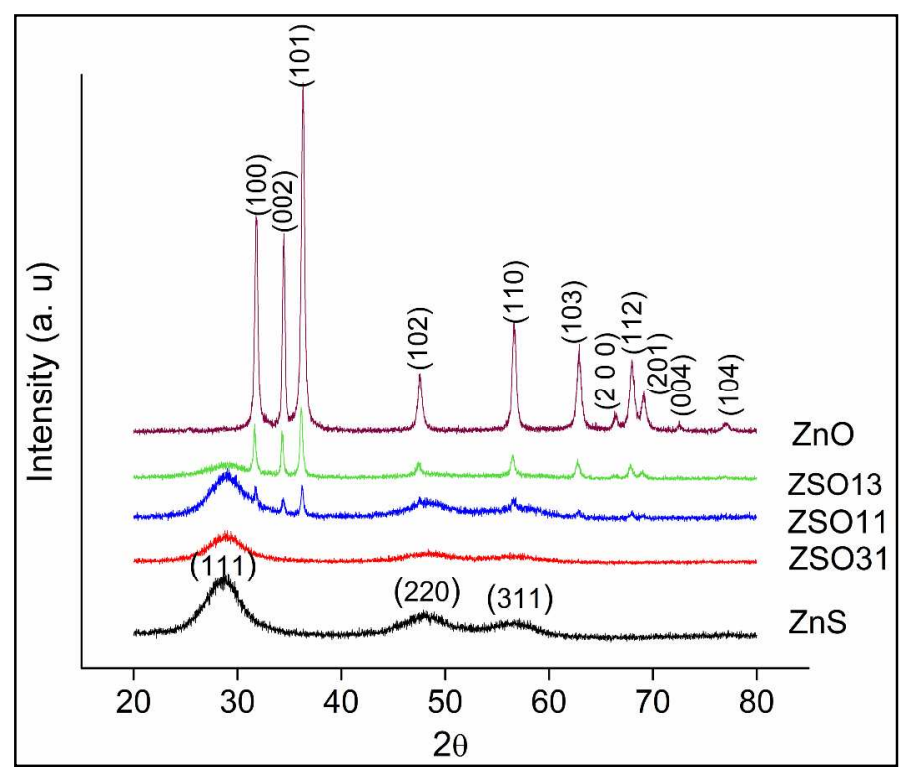

Fig.1 X-ray diffraction pattern of ZnS, ZSO31, ZSO11, ZSO13, and ZnO 
The transmission electron micrographs of the samples presented in Fig. 2 provided the morphological features of synthesized nano composites. Fig. 2a represented the $\mathrm{ZnS}$ nanoparticles obtained by the precipitation of zinc acetate using sodium sulphide. The individual particles were found extremely fine sized and uniform though they appeared agglomerated in the absence of any surface modification. The measurements done on the TEM image of ZnS nanoparticles provided particle size values under $5 \mathrm{~nm}$. On the contrary, the $\mathrm{ZnO}$ precipitation from zinc nitrate resulted in sub-micron sized particles of average size 0.4 microns with a morphology resembling that of rice grains (Fig 2b). The fine precipitates of $\mathrm{ZnS}$ were seen coated over the grain shaped $\mathrm{ZnO}$ particles in the ZSO31 nanocomposite presented in Fig. 2c. The surface coverage of $\mathrm{ZnO}$ by $\mathrm{ZnS}$ nanoparticles were observed also for the ZSO13 composition despite the significant increase in $\mathrm{ZnO}$ concentration. This was primarily ascribed to the high surface area of the synthesized $\mathrm{ZnS}$ particles compared to $\mathrm{ZnO}$. The TEM studies have conclusively confirmed the composite microstructure as $\mathrm{ZnS}$ coated $\mathrm{ZnO}$ particles.

Figure 2B provides the EDAX pattern of the ZSO31 sample which clearly indicated that the particles are composed of the elements of $\mathrm{Zn}, \mathrm{S}$, and $\mathrm{O}$ only. This observation substantiated the XRD results on the phase composition of the ZSO31 sample. The morphology of ZnO particles were further confirmed from SEM micrographs presented in Figure 2C. As observed in TEM, the $\mathrm{ZnO}$ particles were of uniform size and of rice grain type morphology with an approximate length of $400 \mathrm{~nm}$ and diameter of $200 \mathrm{~nm}$. 

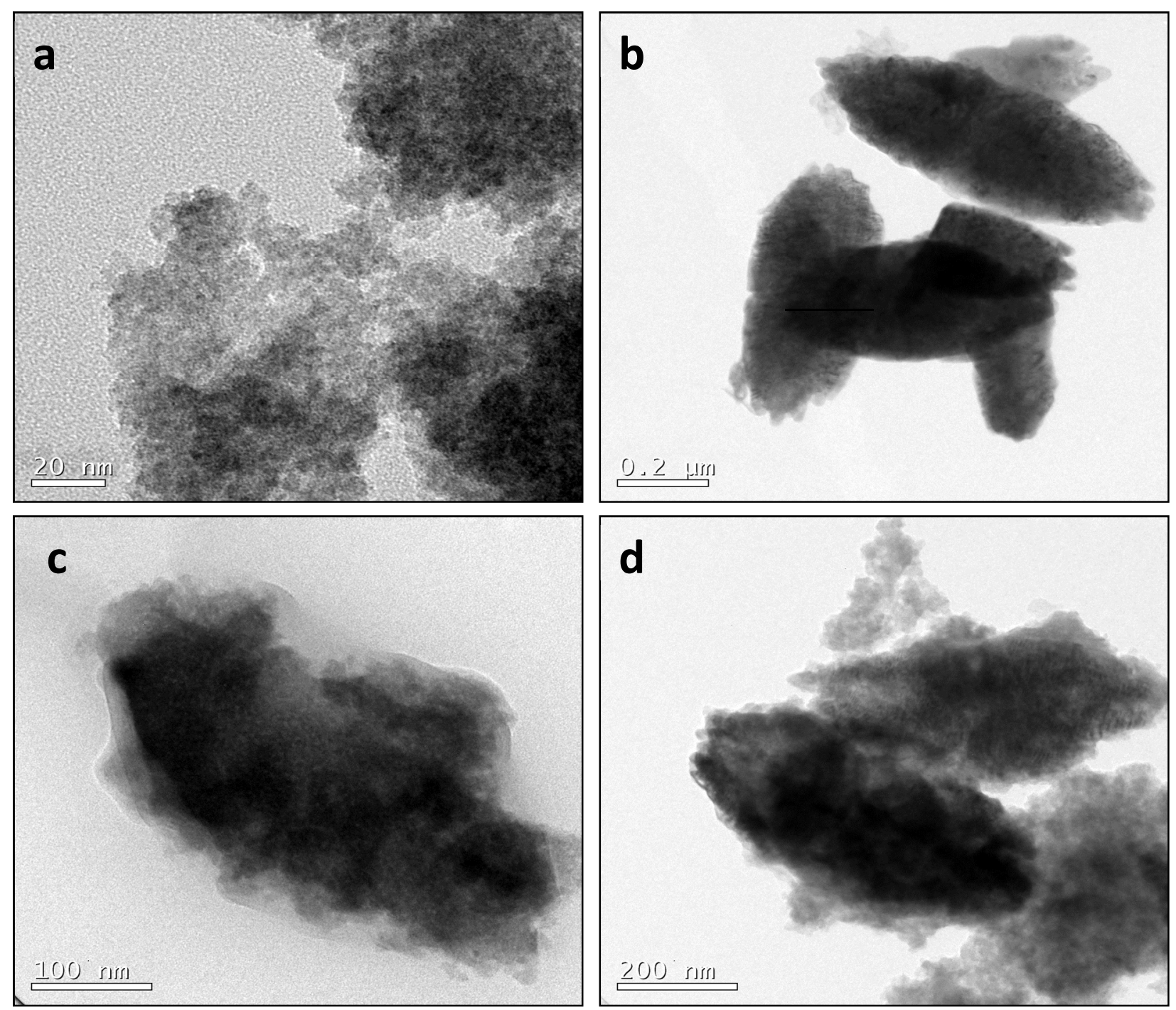

Fig. 2A TEMmicrographs of a) ZnS, b) ZnO) c) ZSO31 and d) ZSO13 
$\mathrm{ZnL}$

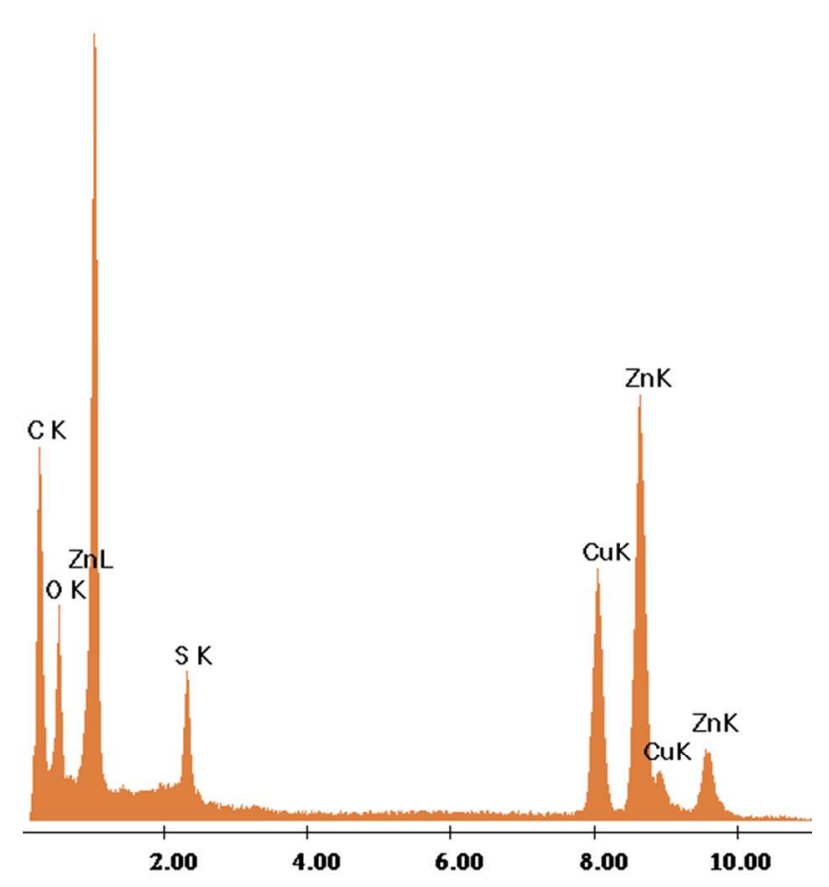

Fig. 2B EDAX spectrum of ZSO31
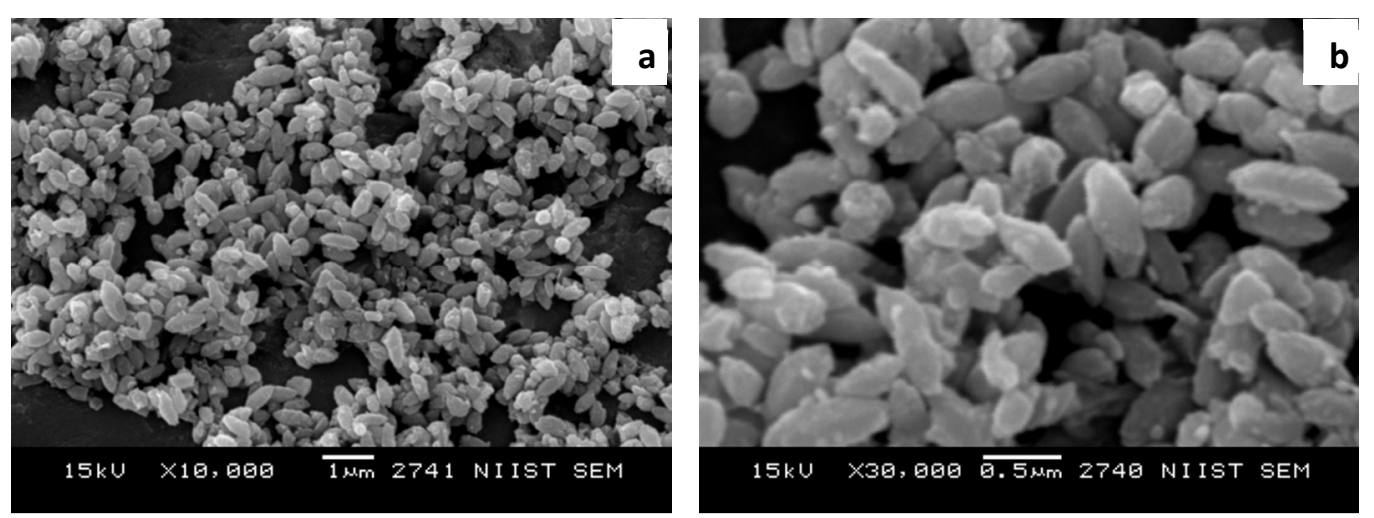

Fig. 2C SEM images of $\mathrm{ZnO}$ submicron particles at a) low b) high magnifications 
The electronic properties of the prepared composite samples were analyzed by the diffused reflectance spectra provided in Fig. 3. The absorbance patterns of samples in the spectral region of 200-400 $\mathrm{nm}$ presented in Fig 3a indicated that the ZnSnano particles possessed an absorption edge at $346 \mathrm{~nm}$ and the $\mathrm{ZnO}$ particles at $382 \mathrm{~nm}$. The nano composites with the three different weight proportions had values intermediate between the two pure samples of $\mathrm{ZnO}$ and $\mathrm{ZnS}$. Addition of $\mathrm{ZnO}$ to $\mathrm{ZnS}$ shifted the absorbance to higher wavelength regions but within that observed for $\mathrm{ZnO}$.

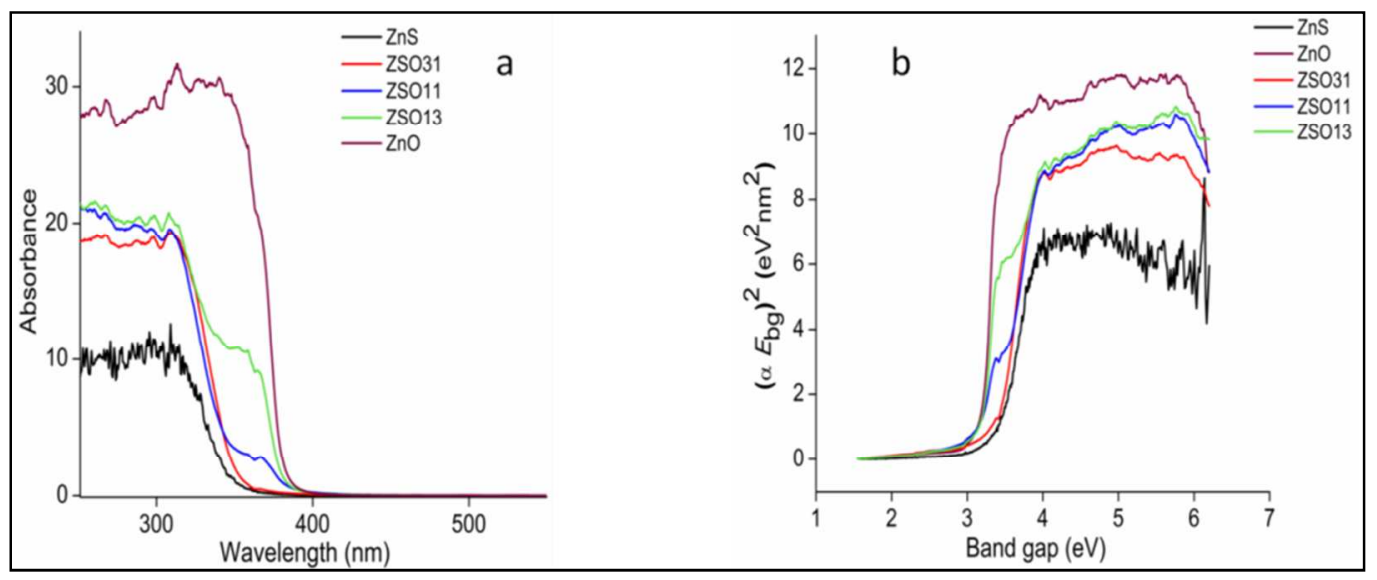

Fig. 4 a. UV-Vis Absorption spectra and b. the corresponding band gap values of ZnS, ZSO31, ZSO11, ZSO13, and ZnO

Fig $3 \mathrm{~b}$ presented the bang gap values estimated using the Tauc plot. The band gap of $\mathrm{ZnS}$ nanoparticles was calculated to be $3.3 \mathrm{eV}$ and was found considerably less than the value of 3.6 reported for bulk $\mathrm{ZnS}$. Sub-micron $\mathrm{ZnO}$ particles possessed $\mathrm{Eg}$ value of 3.0 and was in accordance with reported values. The band gap values of the $\mathrm{ZnS}-\mathrm{ZnO}$ composites were found to 
be in between that of $\mathrm{ZnO}$ and $\mathrm{ZnS}$. The nanocomposite formation facilitated modification of band gap values and absorbance patterns. However, the modifications were not sufficient enough to extend the absorption characteristics to the visible light region.

Table 1 BET Surface Area of samples of $\mathrm{ZnS}-\mathrm{ZnO}$ nanocomposites and their individual constituents

\begin{tabular}{lc}
\hline Sample & $\begin{array}{c}\text { Surface area } \\
\mathbf{m}^{\mathbf{2}} / \mathbf{g}\end{array}$ \\
\hline $\mathrm{ZnS}$ & 170 \\
$\mathrm{ZnO}$ & 2 \\
$\mathrm{ZSO} 31$ & 168 \\
$\mathrm{ZSO} 11$ & 172 \\
$\mathrm{ZSO} 13$ & 97 \\
\hline
\end{tabular}

The surface area values of $\mathrm{ZnS}, \mathrm{ZnO}$ and their composites presented in Table 1 indicated that the pure $\mathrm{ZnS}$ particles derived by the precipitation reaction yielded high surface area values of 170 $\mathrm{m}^{2} / \mathrm{g}$ while the grain shaped $\mathrm{ZnO}$ particles possessed almost negligible surface area values of $\sim 2$ $\mathrm{m}^{2} / \mathrm{g}$. The adsorption isotherms displayed a shape characteristic of surface adsorption in solids. The $\mathrm{ZnS}-\mathrm{ZnO}$ compositions containing up to $50 \mathrm{wt} \% \mathrm{ZnS}$ indicated surface area (Table 1) values as high as that of pure $\mathrm{ZnS}$ particles. The adsorption isotherms presented in Fig. 4 indicated the porous nature of $\mathrm{ZnS}$ and $\mathrm{ZnS}$ rich composites (ZSO11 and ZSO31).

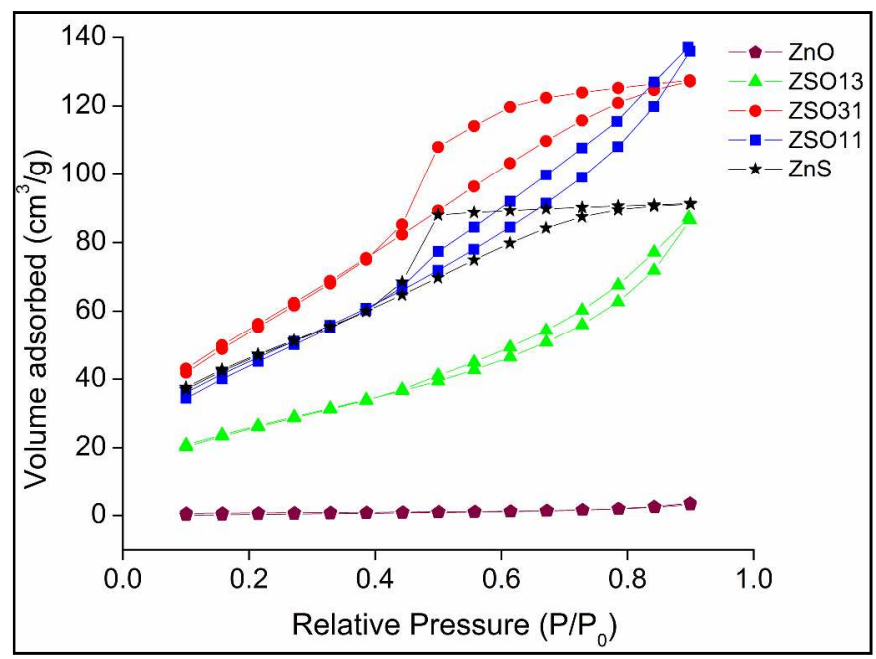


Fig. 5 Nitrogen adsorption-desorption isotherm of ZnS, ZSO31, ZSO11, ZSO13, and ZnO

From the shape of the isotherms and the adsorption values, it was safe to assume that the presence of low amounts of $\mathrm{ZnO}$ has helped to reduce the agglomeration of $\mathrm{ZnS}$ thus providing surface area values higher than the pure $\mathrm{ZnS}$ itself. However, as the $\mathrm{ZnO}$ concentration increased (ZSO13) the composite behaved more like $\mathrm{ZnO}$ with a coating of $\mathrm{ZnS}$ over it.

\subsection{Antifungal Activity}

The minimum inhibitory concentrations (MIC) of the nanocomposites in comparison with the individual constituents tabulated in Table 2 indicated that the MIC of $\mathrm{ZnS}$ : $\mathrm{ZnO}$ compositions in all the proportions studied were much less than that of pure $\mathrm{ZnO}$. Of the compositions, $\mathrm{ZnO}$ was found to possess the highest MIC of $250 \mu \mathrm{g} / \mathrm{ml}$ presumably due to its larger size and poor surface area. The $\mathrm{ZnS}$ nanoparticle displayed MIC value of $64 \mu \mathrm{g} / \mathrm{ml}$ and was considerably lower than that of ZnO. Significant activity was recorded by ZSO31 compositions with MIC value as low as $16 \mu \mathrm{g} / \mathrm{ml}$ against $C$. albicans.

Table 2: Minimum Inhibitory Concentrations (MIC) of samples

\begin{tabular}{lccc}
\hline Photocatalyst & \multicolumn{3}{c}{ MIC $(\mu \mathrm{g} / \mathrm{ml})$} \\
\cline { 2 - 4 } & C. albicans & C. tropicalis & S. cerevisiae \\
\hline $\mathrm{ZnO}$ & 250 & 500 & 1000 \\
$\mathrm{ZnS}$ & 64 & 64 & 500 \\
$\mathrm{ZSO} 31$ & 16 & 32 & 64 \\
\hline
\end{tabular}




\begin{tabular}{llll}
\hline ZSO11 & 32 & 64 & 125 \\
ZSO13 & 64 & 64 & 125 \\
\hline
\end{tabular}

\subsection{Time kill assay}

Time-kill assays for the nanoparticles, on the yeast species investigated,are shown in Fig. 6.

Figures 5 (a-f) represented the time-kill curves of nanoparticles with C. albicans, C. tropicalis and S. cerevisiae, respectively, under light and dark conditions. 

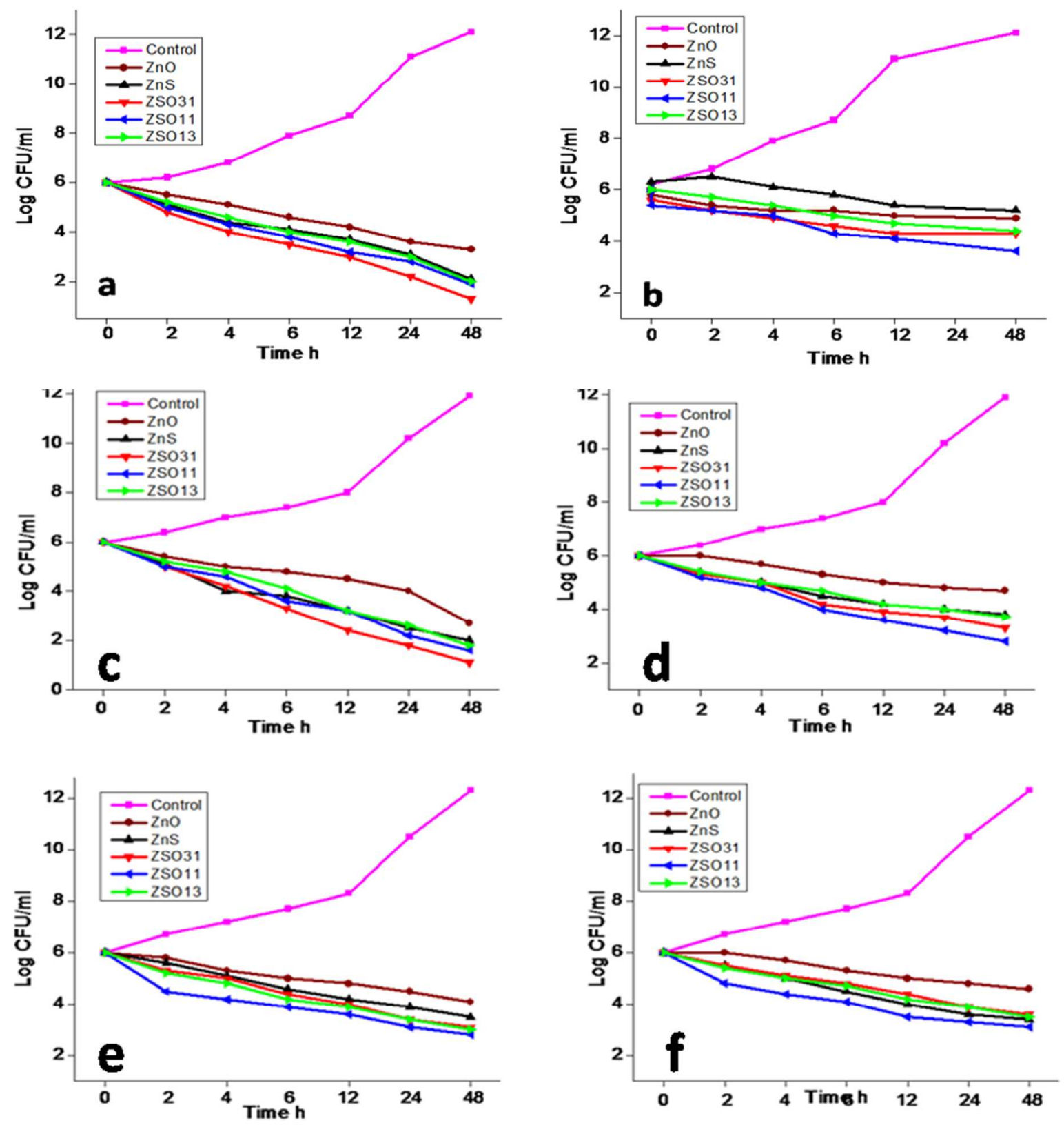

Fig. 6 Time kill curve of C. albicans in (a) light and (b) dark, C. tropicalis in (c) light and (d) dark and S. cerevisiae in (e) light and (f) dark

The time-kill assay which is a measure of the rate of killing of microbes, provided a comparison of the antifungal property of the investigated samples. In the absence of nanoparticles there was an exponential growth of microbial colonies in all the investigations under light and dark conditions. It was also evident from the curves that the reduction in the growth of microbial 
colonies was more pronounced in the presence of light confirming that the ROS generation by the photocatalytic nanoparticles was a dominating factor for the microbial growth resistance. On quantification, a value of $6 \log _{10}(\mathrm{CFU} / \mathrm{ml})$ at the start of experiment was found to be reduced to a value of $1.3 \log _{10}(\mathrm{CFU} / \mathrm{ml})$ for the sample ZSO31 under light. However, the same experiments under dark conditions revealed only a nominal reduction to a value of $4.3 \log _{10}(\mathrm{CFU} / \mathrm{ml})$ for ZSO31. The maximum reduction observed under dark condition was, for the sample ZSO11, to a value of $3.5 \log _{10}(\mathrm{CFU} / \mathrm{ml})$. Detailed analysis of all the three yeast species testified improved efficiency of the nanocomposites in the presence of light.

The antifungal activity observed under dark conditions was ascribed primarily due to mechanisms associated with the efflux of metal ions in solutions, as reported earlier. ${ }^{3,}{ }^{39-41}$ Zinc ions are known to inhibit multiple activities in the microbe cell, such as glycolysis, transmembrane proton translocation, and acid tolerance. In all the experiments, the nanocomposite particles were found to be more efficient compared to the individual particles of $\mathrm{ZnO}$ and $\mathrm{ZnS}$. Among the three yeast species investigated, the effectiveness of nanocomposites for growth inhibition was found to be more against the candida species than the $S$. cerevisiae. It was also observed that though the nanocomposites were better in reducing the microbial burden, there were slight variations in the response of $\mathrm{ZnS}-\mathrm{ZnO}$ compositions towards a particular yeast species. In the presence of light the efficiency of ZSO31 composition was the best for the candidal species while ZSO11 was the most effective against S. cerevisiae. The variation in effectiveness of the tested nanocomposites against the different yeast species was attributed to the differences in microbial cell wall structure, cell physiology, metabolism, degree of contact or surface charge of yeast cell.

\subsection{Growth curve}


The growth curves of C. albicans, C. tropicalis and S. cerevisiae in the presence of nanoparticles under light and dark conditions are presented in Figures 6 (a-f) respectively. The presence of nanoparticles retarded the growth of all the yeast species significantly in the presence of light and the effect was more pronounced for the nanocomposites than the individual particles of $\mathrm{ZnO}$ and $\mathrm{ZnS}$. Among the different compositions of nanocomposites, a conclusive evidence of one efficient composition was however not obtained. Significant reduction in the growth of $C$. albicanswas recorded by the combination ZSO31 and the maximum reduction was recorded between 4 and $12 \mathrm{~h}(p<0.05)$. At $48 \mathrm{~h}$ this combination reduced $>99 \%$ of Candida species. Regrowth was not recorded for the combinations and individual components. 

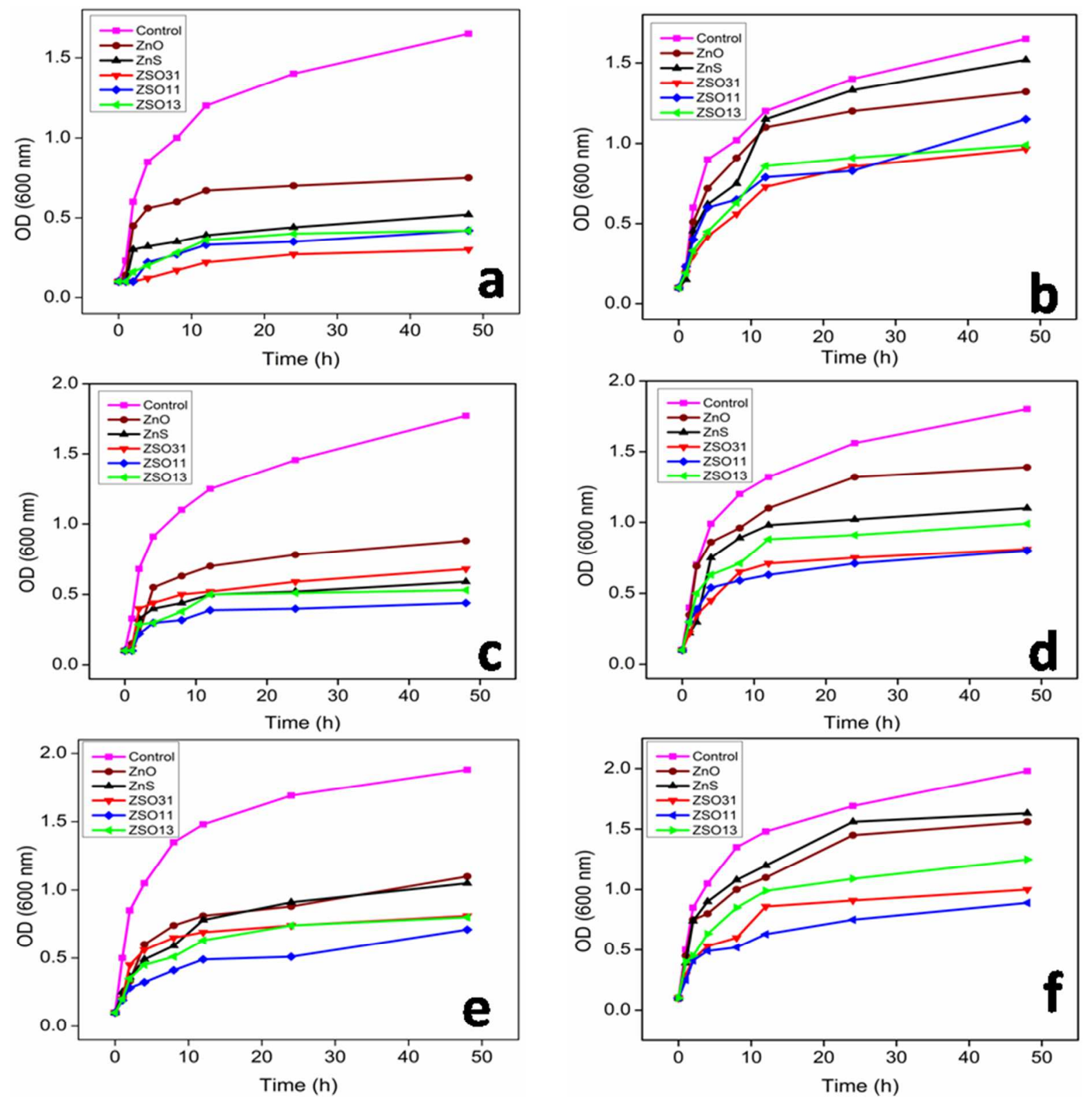

Fig. 7 Growth curve of C. albicans in (a) light and (b) dark, C. tropicalis in (c) light and (d) dark and $S$. cerevisiae in (e) light and (f) dark

Of the three yeast species investigated, the effectiveness for growth inhibition was found to be in the order $C$. albicans $>C$. tropicalis $>S$. cerevisiae. It was also observed that there were slight variations in the response of $\mathrm{ZnS}-\mathrm{ZnO}$ compositions towards a particular yeast species. Under dark conditions, the growth patterns of microbes in presence of the individual nanoparticles 
closely resembled that of the control sample. The individual nanoparticles of $\mathrm{ZnS}$ and $\mathrm{ZnO}$ were found to be ineffective in growth inhibition against all the yeast species tested. The nanocomposites were relatively better though variations were observed in their effectiveness against the tested yeast species

\subsection{Fungal membrane permeabilisation}

Propidium iodide (PI), a membrane impermeable, nucleic acid staining dye, upon binding to double stranded nucleic acid gave a red fluorescence on excitation by a $480 \mathrm{~nm}$ laser. PI can only enter those cells, which have permeable membranes. Fungal cell membrane permeabilisation was thus studied for the nanoparticles of $\mathrm{ZnS}, \mathrm{ZnO}$ and the nanocomposites of $\mathrm{ZnO}-\mathrm{ZnS}$. Since the maximum cell growth reduction was observed for C. albicans, PI uptake assay was monitored only for $C$. albicans. Incubation of the nanocomposite with $C$. albicans cells resulted in PI uptake by the cells as monitored by confocal microscopy (Figure 7). We observed significant increase in the PI associated fluorescence for the $\mathrm{ZnS}-\mathrm{ZnO}$ nanocomposite than the individual constituents of $\mathrm{ZnO}$ and $\mathrm{ZnS}$. This was a clear indication of increase in the membrane permeabilisation in Candida cells facilitated by the cell membrane rupture by ROS. No PI fluorescence was observed in control.

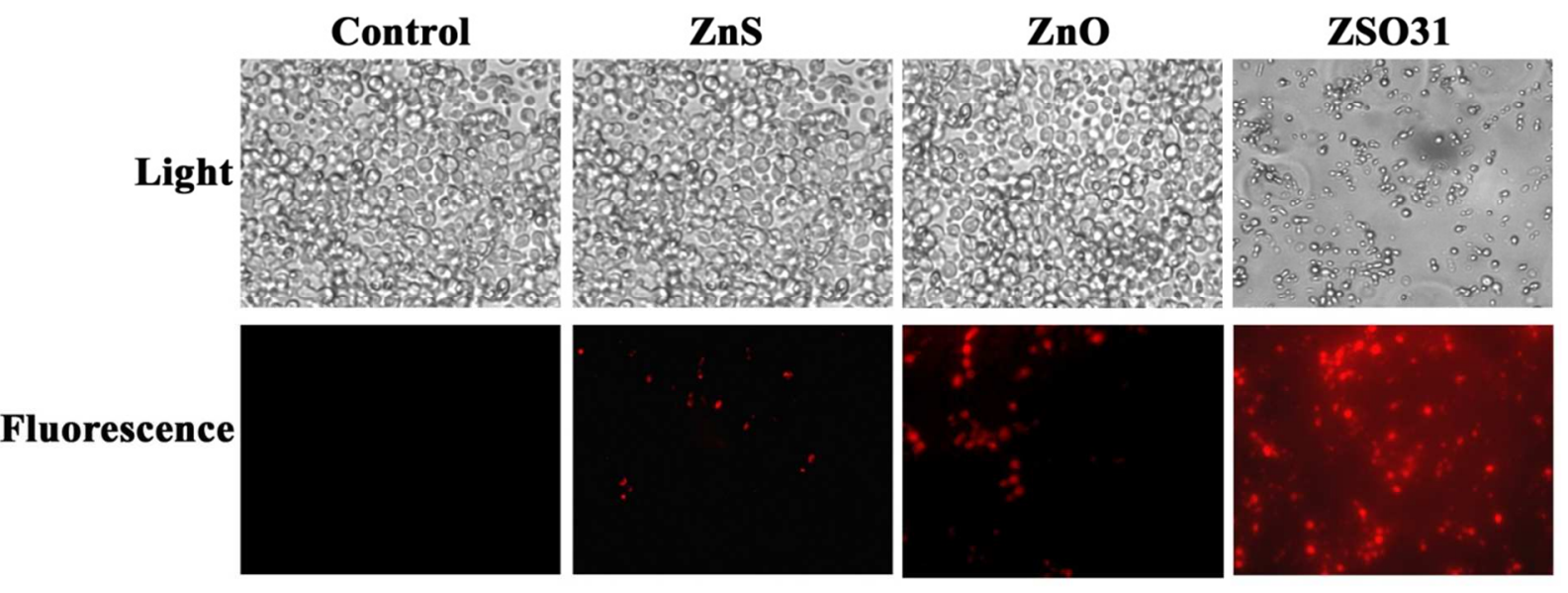


Fig.8 Light microscope and confocal microscope images of PI stained C. albicans treated with ZSO31 and individual constituents

\subsection{Role of intracellular ROS}

The role of ROS generated by nanoparticles against Candida spp. is shown in Fig. 8. The most likely mechanism imparting antifungal activity in nanoparticles was the generation of ROS. The $\mathrm{ZnS}-\mathrm{ZnO}$ nanocomposites generated more ROS than the individual nanoparticles against the tested Candidaspp. The nanocomposite samples with $4 \mathrm{mM}$ histidine showed growth profile, which more or less matched that of the control sample (without nanoparticles) indicating that the generated ROS was effectively scavenged by histidine. The results thus obtained revealed that the antifungal activity of the nanoparticles is primarily related to the ROS mechanism. 

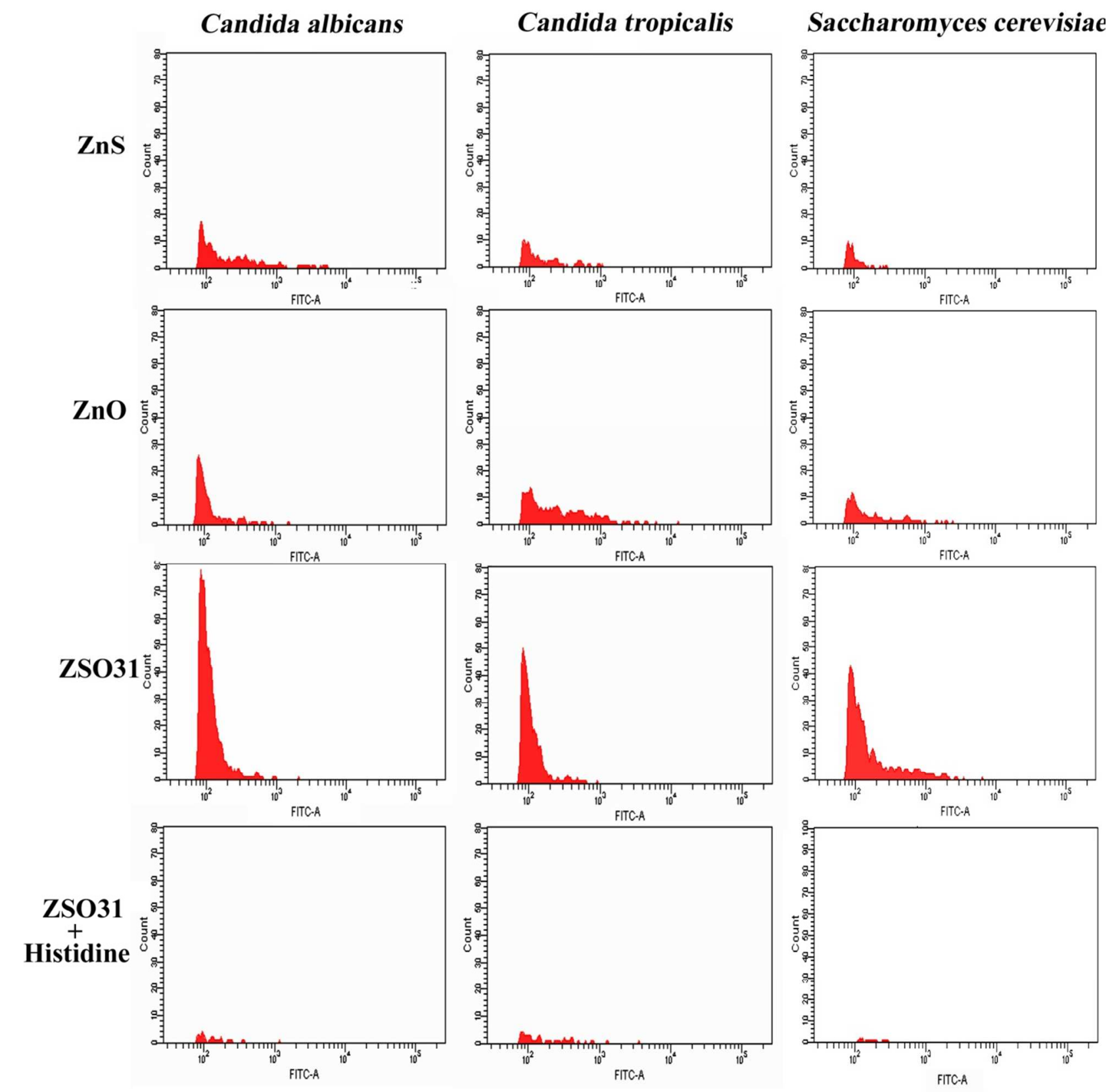

Fig. 9 Flowcytometric Analysis on the role of ROS Formation in Yeast spp.

\section{Discussion}

The $\mathrm{ZnS}-\mathrm{ZnO}$ core shell nanocomposites obtained by the surface coverage of sub-micron sized $\mathrm{ZnO}$ particles by the nanoparticles of $\mathrm{ZnS}$ have displayed higher antifungal activity than their constituent individual particles. The red shift observed for composites towards the $400 \mathrm{~nm}$ mark and the lowering of band gap to values less than $3 \mathrm{eV}$ imparted improved photocatalytic action in 
the nanocomposites. The conduction band of $\mathrm{ZnS}$ possessed more negative potential than that of the $\mathrm{ZnO}$ while the valence band potential of $\mathrm{ZnO}$ is more positive than $\mathrm{ZnS}$. The formation of $\mathrm{ZnS}-\mathrm{ZnO}$ interfaces facilitated transfer of electrons from $\mathrm{ZnS}$ to the conduction band of $\mathrm{ZnO}$ and holes to the valence band of $\mathrm{ZnS}$ from the corresponding band of $\mathrm{ZnO}$. The major factor that enabled the nanocomposite photocatalysts to out- perform their individual constituents was the enhanced charge separation achieved by tuning the energy band of $\mathrm{ZnS}$ with the lower potential of $\mathrm{ZnO}$ leading to improved efficiency through reduced recombination. The migration of charge carriers to the surfaces of $\mathrm{ZnO}$ and $\mathrm{ZnS}$ thus generated hydroxyl radical and other reactive oxygen species by reacting with moisture and oxygen. The schematic illustration of the possible mechanism is presented in Figure 9.

The antimicrobial effect of nanoparticles is ascribed primarily to the two mechanisms of ROS generation and metal ion efflux in solutions ${ }^{3,42-43}$. The ROS generation induced cytotoxicity and caused cell decay in yeast spp. as it exceeded the antioxidative capacity of the cell. This mechanism is amply supported by literature data for a variety of nanoparticles and is comprehensively illustrated by the use of radical scavengers like histidine ${ }^{2,44-45}$. In the present work, the antifungal activities were tested under both indoor light illumination and under dark conditions. The normal laboratory conditions involving fluorescent lighting was sufficient to generate charge carriers, leading eventually to the generation of ROS as reported earlier ${ }^{46}$. A comparative evaluation of the effectiveness of the nanocomposites under light and dark conditions revealed that the performance was better in the presence of light. The nanocomposites as well as their individual constituents displayed absorption only in the wavelengths region of 340-380 $\mathrm{nm}$ and hence are considered to be UV responsive only. The fact that the antimicrobial activity was best observed in the presence of light therefore suggested that the $4 \%$ UV light 
fraction in indoor fluorescent lighting was sufficient to induce the required photoactivity for ROS generation, as has been observed before ${ }^{46}$. Time kill assay and growth curve analysis also suggested enhanced activity under indoor lighting than in the dark conditions substantiating the role of ROS generation by the photocatalysts. Nevertheless, the observance of greatly diminished activity under dark conditions is presumed to be due to metal ion efflux as has been proven in the case of $\mathrm{ZnS}$ before ${ }^{2}$. Hence the synergy of ROS and metal ion efflux is believed to be the dominant mechanism behind the enhanced antifungal activity of nanocomposite photocatalysts. The observation that the nanocomposites out-performed the individual nanoparticles in their effectiveness against all the tested yeast species confirmed the dominance of ROS over efflux mechanism. Additionally, the inhibitory role of ROS was further evidenced by the cell permeabilisation studies using propidium iodide, which resulted in enhanced fluorescence in nanocomposites compared to the individual particles of $\mathrm{ZnO}$ and $\mathrm{ZnS}$. The increased uptake of PI into the yeast cells was a clear indication of ROS induced cell rupture as PI specifically stains only the damaged cells.

Under the same experimental conditions, the nanocomposite of $\mathrm{ZnS}-\mathrm{ZnO}$ demonstrated enhanced anticandidal activity with very low MIC values than that reported previously for the individual constituents of $\mathrm{ZnO}$ and $\mathrm{ZnS}^{2,10,44-45,47}$. The flow cytometry results confirmed the increased levels of ROS generation in ZSO31 composites against all the yeast species and were attributed to the synergistic nanocomposite effect in combination with higher surface area values $\left(168 \mathrm{~m}^{2} / \mathrm{g}\right)$. It was also reported that chemisorbed $\mathrm{OH}$ species on $\mathrm{ZnO}$ surfaces in water can also lead to ROS formation ${ }^{48}$. However, in the present study none of the experimental evidences supported significant ROS generation by pure $\mathrm{ZnO}$ particles as they were of larger sizes and negligible surface area. 


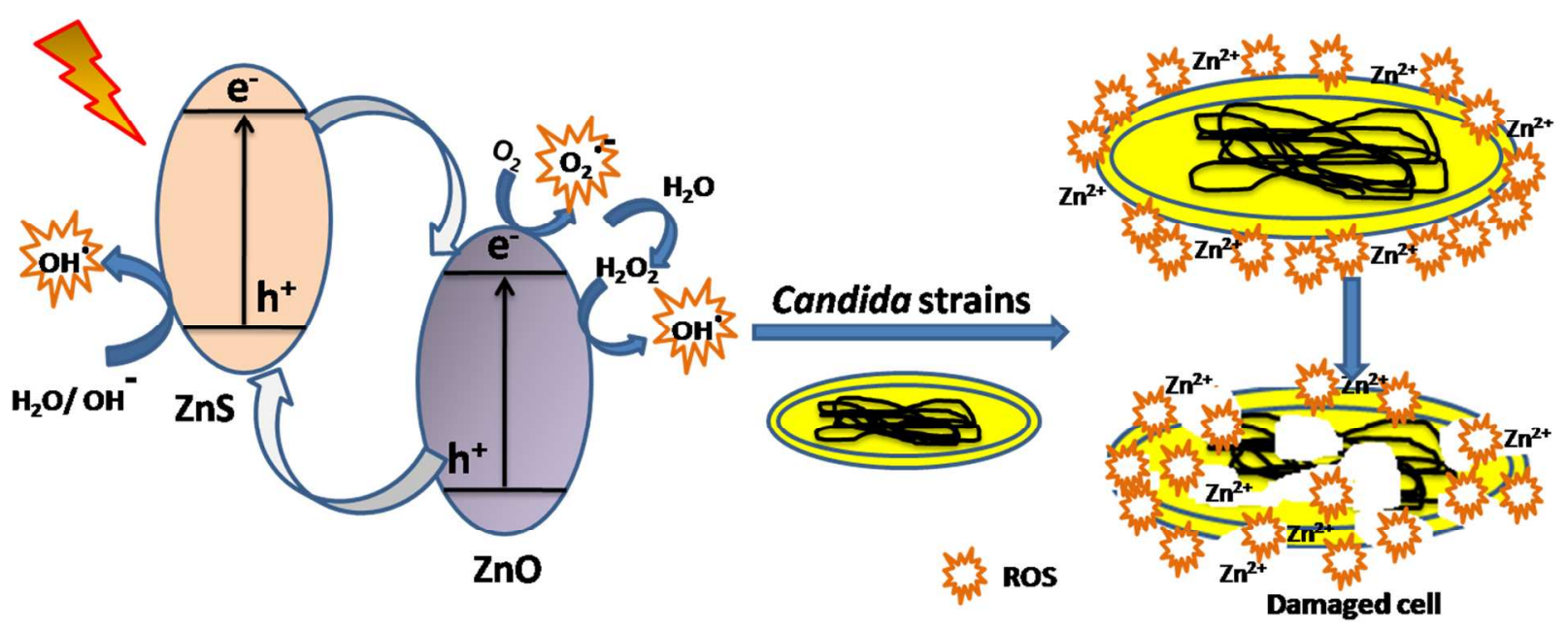

Fig. 10 Schematic representation of band alignment leading to antifungal activity

The present study has thus lead to the development of $\mathrm{ZnS}-\mathrm{ZnO}$ nanocomposites with enhanced antifungal activity mediated by ROS generation under laboratory lighting conditions. The mild activity observed under dark conditions indicated the possibility of metal ion efflux also contributing to the killing of yeast cells. The synergistic effect of $\mathrm{ZnS}-\mathrm{ZnO}$ nanocomposites, as illustrated schematically in Fig 9, provided enhanced charge separation leading to minimum recombination of charge carriers. This has in turn resulted in the increased effectiveness of the $\mathrm{ZnS}-\mathrm{ZnO}$ nanocomposites compared to their individual constituents.

\section{Conclusions}

$\mathrm{ZnS}-\mathrm{ZnO}$ nanocomposites prepared by a simple precipitation method at room temperature have displayed considerable anti-fungal activity against C. albicans, C. tropicalis and S. cerevisiae under normal laboratory lighting conditions. Photo induced ROS generation aided by the synergistic effects of nanocomposite architecture is the primary mechanism responsible for this enhanced performance. The inhibitory role of ROS was further confirmed by experimental 
results obtained through growth curve analysis, time kill assay and cell permeabilisation studies.

The studies revealed that ambient laboratory lighting conditions are conducive for the optimal performance of the nanocomposites in controlling the microbial growth of the tested yeast species. The diminished activity observed under dark conditions is ascribed to the metal ion efflux observed for zinc in solutions. The improved anticandidal activity with minimum inhibitory concentrations provides wide scope for practical applications aimed at alleviating the harmful effects of environmental contaminants.

\section{Acknowledgements}

The authors gratefully acknowledge the Council of Scientific and Industrial Research (CSIR, Government of India) for funding the $12^{\text {th }}$ five year plan project on "IntelCoat" (CSC0114). Authors P. Suyana and K. G. K. Warrier acknowledge CSIR for their fellowships. S. Nishanth Kumar thanks KSCSTE for providing a postdoctoral fellowship. Mr. Kiran Mohan, CSIR-NIIST is acknowledged for TEM Imaging.

\section{References}

1. S. Ghosh, V. S. Goudar, K. G. Padmalekha, S. V. Bhat, S. S. Indi and H. N. Vasan, RSC $A d v ., 2012,2,930-940$.

2. P. Suyana, S. N. Kumar, B. S. D. Kumar, B. N. Nair, S. C. Pillai, A. P. Mohamed, K. G. K. Warrier and U. S. Hareesh, RSC Adv., 2014, 4, 8439-8445.

3. A. S. Haja Hameed, C. Karthikeyan, S. Sasikumar, V. Senthil Kumar, S. Kumaresan and G. Ravi, J. Mater. Chem. B, 2013, 1, 5950-5962.

4. G. Applerot, J. Lellouche, N. Perkas, Y. Nitzan, A. Gedanken and E. Banin, RSC Adv., 2012, 2, 2314-2321.

5. N. Perkas, A. Lipovsky, G. Amirian, Y. Nitzan and A. Gedanken, J. Mater. Chem. B, 2013, 1, 5309-5316.

6. I. Perelshtein, E. Ruderman, N. Perkas, T. Tzanov, J. Beddow, E. Joyce, T. J. Mason, M. Blanes, K. Molla, A. Patlolla, A. I. Frenkel and A. Gedanken, J. Mater. Chem. B, 2013, 1, 1968-1976.

7. G. Tong, F. Du, W. Wu, R. Wu, F. Liu and Y. Liang, J. Mater. Chem. B, 2013, 1, 26472657. 
8. P. K. J. Robertson, J. M. C. Robertson and D. W. Bahnemann, J. Hazard.Mater., 2012, 211-212, 161-171.

9. H. Kong, J. Song and J. Jang, Environ. Sci. Technol., 2010, 44, 5672-5676.

10. M. Fang, J.-H.Chen, X.-L.Xu, P.-H.Yang and H. F. Hildebrand, Int. J. Antimicrob. Agents, 2006, 27, 513-517.

11. Q. Li, S. Mahendra, D. Y. Lyon, L. Brunet, M. V. Liga, D. Li and P. J. J. Alvarez, Water Res, 2008, 42, 4591-4602.

12. C.-J. Chung, H.-I.Lin, H.-K.Tsou, Z.-Y.Shi and J.-L.He, J. Biomed. Mater. Res. Part B Appl. Biomater., 2008, 85B, 220-224.

13. C. Li, R. Younesi, Y. Cai, Y. Zhu, M. Ma and J. Zhu, Appl. Catal. B, 2014, 156-157, 314-322.

14. G. Li, J. Zhai, D. Li, X. Fang, H. Jiang, Q. Dong and E. Wang, J. Mater. Chem., 2010, 20, 9215-9219.

15. Y. Li, J. Niu, W. Zhang, L. Zhang and E. Shang, Langmuir, 2014, 30, 2852-2862.

16. J. Liu, L. Liu, H. Bai, Y. Wang and D. D. Sun, Appl. Catal. B, 2011, 106, 76-82.

17. K. R. Raghupathi, R. T. Koodali and A. C. Manna, Langmuir, 2011, 27, 4020-4028.

18. N. Cioffi, M. Rai, (Eds.), Nano-Antimicrobials Progress and Prospects, SpringerVerlag, Heidelberg, 1 edn, 2012.

19. J. T. Seil and T. J. Webster, Int. J. Nanomedicine, 2012, 7, 2767-2781.

20. J. Zhang, Y. Wang, J. Zhang, Z. Lin, F. Huang and J. Yu, ACS Appl. Mater. Interfaces, 2013, 5, 1031-1037.

21. Q. Zhao, Y. Xie, Z. Zhang and X. Bai, Cryst. Growth Des., 2007, 7, 153-158.

22. J.-S. Hu, L.-L. Ren, Y.-G. Guo, H.-P. Liang, A.-M. Cao, L.-J. Wan and C.-L. Bai, Angew. Chem. Int. Ed., 2005, 44, 1269-1273.

23. S. H. Elder, F. M. Cot, Y. Su, S. M. Heald, A. M. Tyryshkin, M. K. Bowman, Y. Gao, A. G. Joly, M. L. Balmer, A. C. Kolwaite, K. A. Magrini and D. M. Blake, J. Am. Chem. Soc., 2000, 122, 5138-5146.

24. S. K. Poznyak, D. V. Talapin and A. I. Kulak, J. Phys. Chem. B, 2001, 105, 4816-4823.

25. J. Lahiri and M. Batzill, J. Phys. Chem. C, 2008, 112, 4304-4307.

26. S. G. Hussain, D. Liu, X. Huang, S. Ali and M. H. Sayyad, J. Phys. Chem. C, 2008, 112, 11162-11168.

27. J. Geng, B. Liu, L. Xu, F.-N.Hu and J.-J. Zhu, Langmuir, 2007, 23, 10286-10293.

28. P. Chen, L. Gu and X. Cao, CrystEngComm, 2010, 12, 3950-3958.

29. X. M. Shuai and W. Z. Shen, J. Phys. Chem. C, 2011, 115, 6415-6422.

30. M.-Y. Lu, J. Song, M.-P.Lu, C.-Y.Lee, L.-J. Chen and Z. L. Wang, ACS Nano, 2009, 3, 357-362.

31. W. Jia, B. Jia, F. Qu and X. Wu, Dalton Trans., 2013, 42, 14178-14187.

32. X. Wang, P. Gao, J. Li, C. J. Summers and Z. L. Wang, Adv. Mater., 2002, 14, 17321735. 
33. X. Wu, P. Jiang, Y. Ding, W. Cai, S. Xie and Z. L. Wang, Adv. Mater., 2007, 19, 23192323.

34. L. Hu, J. Yan, M. Liao, H. Xiang, X. Gong, L. Zhang and X. Fang, Adv. Mater.2012, 24, 2305-2309.

35. X. Huang, M. Wang, M.-G.Willinger, L. Shao, D. S. Su and X.-M.Meng, ACS Nano, 2012, 6, 7333-7339.

36. C. P. LeBel, H. Ischiropoulos and S. C. Bondy, Chem. Res. Toxicol., 1992, 5, 227-231.

37. D.-H. Kim, D. G. Lee, K. L. Kim and Y. Lee, Eur. J. Biochem., 2001, 268, 4449-4458.

38. I. K. Maurya, C. K. Thota, S. D. Verma, J. Sharma, M. K. Rawal, B. Ravikumar, S. Sen, N. Chauhan, A. M. Lynn, V. S. Chauhan and R. Prasad, J. Biol. Chem., 2013, 288, 16775-16787.

39. R. Brayner, R. Ferrari-Iliou, N. Brivois, S. Djediat, M. F. Benedetti and F. Fiévet, Nano Lett., 2006, 6, 866-870.

40. M. Li, L. Zhu and D. Lin, Environ. Sci. Technol., 2011, 45, 1977-1983.

41. N. M. Franklin, N. J. Rogers, S. C. Apte, G. E. Batley, G. E. Gadd and P. S. CaseyEnviron. Sci. Technol., 2007, 41, 8484-8490.

42. H. Yang, C. Liu, D. Yang, H. Zhang and Z. Xi, J. Appl. Toxicol., 2009, 29, 69-78.

43. J. W. Rasmussen, E. Martinez, P. Louka and D. G. Wingett, Exp. Opin. Drug Deliv., 2010, 7, 1063-1077.

44. L. Anat, N. Yeshayahu, G. Aharon and L. Rachel, Nanotechnology, 2011, 22, 105101.

45. M. Shoeb, R. S. Braj, A. K. Javed, K. Wasi, N. S. Brahma, B. S. Harikesh and H. N. Alim, Adv. Nat. Sci.: Nanosci. Nanotechnol., 2013, 4, 035015.

46. N. Jones, B. Ray, K. T. Ranjit and A. C. Manna, FEMS Microbiol. Lett., 2008, 279, 7176.

47. Y. Wang, Q. Zhang, C.-1. Zhang and P. Li, Food Chem., 2012, 132, 419-427.

48. G. Applerot, A. Lipovsky, R. Dror, N. Perkas, Y. Nitzan, R. Lubart and A. Gedanken, Adv. Funct. Mater., 2009, 19, 842-852. 